Check for updates

Cite this: RSC Adv., 2019, 9, 32034

\title{
Computational fluid dynamics simulation as a tool for optimizing the hydrodynamic performance of membrane bioreactors
}

\begin{abstract}
Yan Jin, ${ }^{a}$ Cheng-Lin Liu, (DD *ab Xing-Fu Song (D) ${ }^{\text {ab }}$ and Jian-Guo Yu*ab
The hydrodynamic properties and shear stresses experienced by a membrane bioreactor (MBR) are directly related to its rate of membrane fouling. In this study, computational fluid dynamic models have been combined with cold model PIV experimental studies to optimize the performance properties of MBRs. The effects of membrane module height, number of aeration tubes and membrane spacing on liquid phase flow rates, gas holdup and shear stresses at the membrane surface have been investigated. It has been found that optimal MBRs experience the greatest shear forces on their surfaces at a distance of $250 \mathrm{~mm}$ from the aeration tube, around the 7 aeration tubes used to introduce gas and at the $40 \mathrm{~mm}$ spacings between the membrane sheets. Use of an aeration intensity of between 0.02 and 0.47 $\mathrm{m}^{3} \mathrm{~min}^{-1}$ generated shear stresses that were 50-85\% higher than the original MBR for the same aeration intensity, thus affording optimal membrane performance that minimizes membrane fouling.
\end{abstract}

Received 26th August 2019
Accepted 1st October 2019

DOI: 10.1039/c9ra06706j

rsc.li/rsc-advances model for the cost-effective optimization of MBR and the model further revealed that the high nitrogen removal efficiency $(>90 \%)$ was achieved due to the high recirculation ratio driven by airlift force without destroying the oxygen deprivation and enrichment in the anoxic and oxic zone, respectively. Ndinisa et $a{ }^{17}{ }^{17}$ used CFD to simulate gas-liquid two-phase flow in immersed flat membrane MBRs to predict gas phase velocities, liquid phase velocities and membrane surface shear stress values during aeration. Brannock et al. ${ }^{\mathbf{1 8 , 1 9}}$ used CFD to investigated the effects of aeration and membrane configuration such as size and position of inlets, baffles, or membrane orientation on the overall membrane performance. However, MBR hollow fiber membrane model contains large numbers of membrane filaments that adopt a fluid-solid coupling state during filtration that increases the difficulty of producing accurate calculations. Wang et al. ${ }^{20}$ used an alternative porous medium in their MBR calculation model to develop a method based on experimental determination of the resistance coefficient of the fluid flowing through the hollow fiber membrane. This porous medium model was coupled with a 3D multiphase model to improve the accuracy of the calculations used. Zamani et $a .^{21}$ developed a fluid-solid coupling model based on fluid and structural mechanic governing equations, which predicted that enhanced vibrational shear forces are effective for reducing membrane fouling. Wang et al. ${ }^{22}$ developed a model coupled the Navier-Stokes and Darcy Brinkman equations to simulate a complete filtration run. Radaei et al. ${ }^{23}$ developed a 3D CFD model to the study shear stress induced by spherical cap bubbles in hollow fibre membrane modules.

After several decades of development, Particle Image Velocimetry (PIV) is now recognized as a mature technology for $2 \mathrm{D}$ 


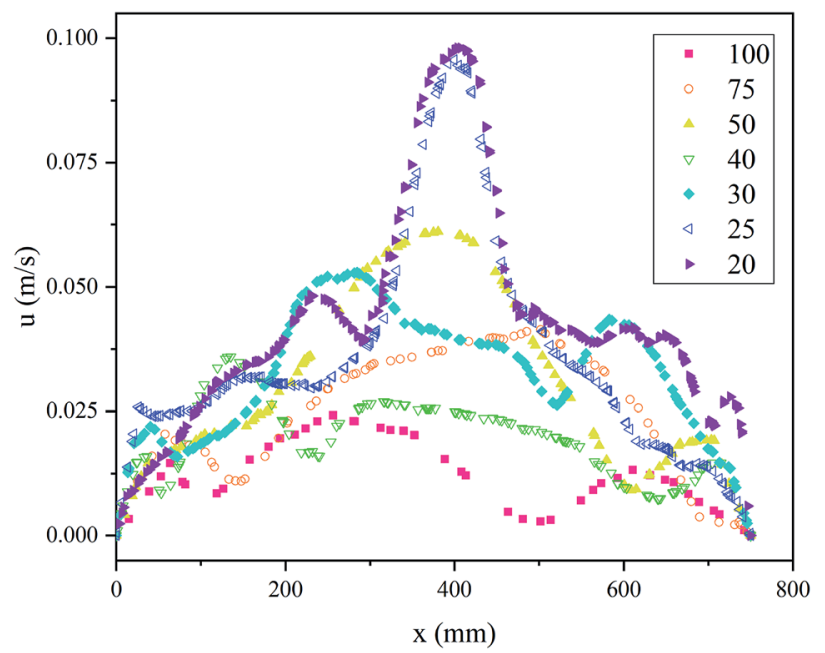

Fig. 1 Effect of grid independence on simulation results for different mesh sizes.

flow field measurement. For example, PIV is widely used throughout the chemical industry for the study of flow field distributions in stirred tank reactors, ${ }^{24}$ at gas-evolving electrodes, ${ }^{25}$ in bubble columns ${ }^{26}$ and flat sheet MBR. ${ }^{27}$ For example, Liu et $a .^{28}$ have used PIV to investigate the hydrodynamic characteristics of two-phase flow fields at gas-evolving electrodes, whilst Leslie $e t$ al. ${ }^{29}$ used PIV to determine the flow states in an aerated bench scale MBR.

This study has used CFD to improve the hydrodynamics of MBR through modification of their structures, including an examination of the effects of changing the height of the membrane, the number of aeration tubes and membrane spacings. The mathematical models developed have been validated through cold testing experiments using PIV technology. Finally, the hydrodynamic characteristics of standard and optimized MBR have been measured under different gas flow rate to evaluate their comparative efficiencies.

\section{Simulation procedures}

Gas-liquid two-phase or gas-liquid-solid three-phase flow modelling approaches have been used to optimise the performance of various types of sewage treatment and chemical reactors. ${ }^{30}$ MBRs are often modelled as a three-phase mixing system, with water used as the continuous phase and air and sludge treated as a dispersed phase. Sludge distribution is relatively uniform because its density is close to that of water, so they can be combined into a continuous phase and treated as a two-phase system.

Two different approaches have been developed to simulate multiphase flow, based on Lagrangian or Eulerian models. ${ }^{31}$ The former method employs liquid as the continuous phase and bubbles considered as the discrete phase, which enables motion trajectories to be tracked in each discrete phase. The latter method considers the two phases to be a continuous phase that coexist at the same spatial point, thus enabling processes to be modelled using their respective momentum, mass, and energy transfer equations. The aeration tube air flotation design used in MBR systems generates a large number of bubbles, with large computational resources required to

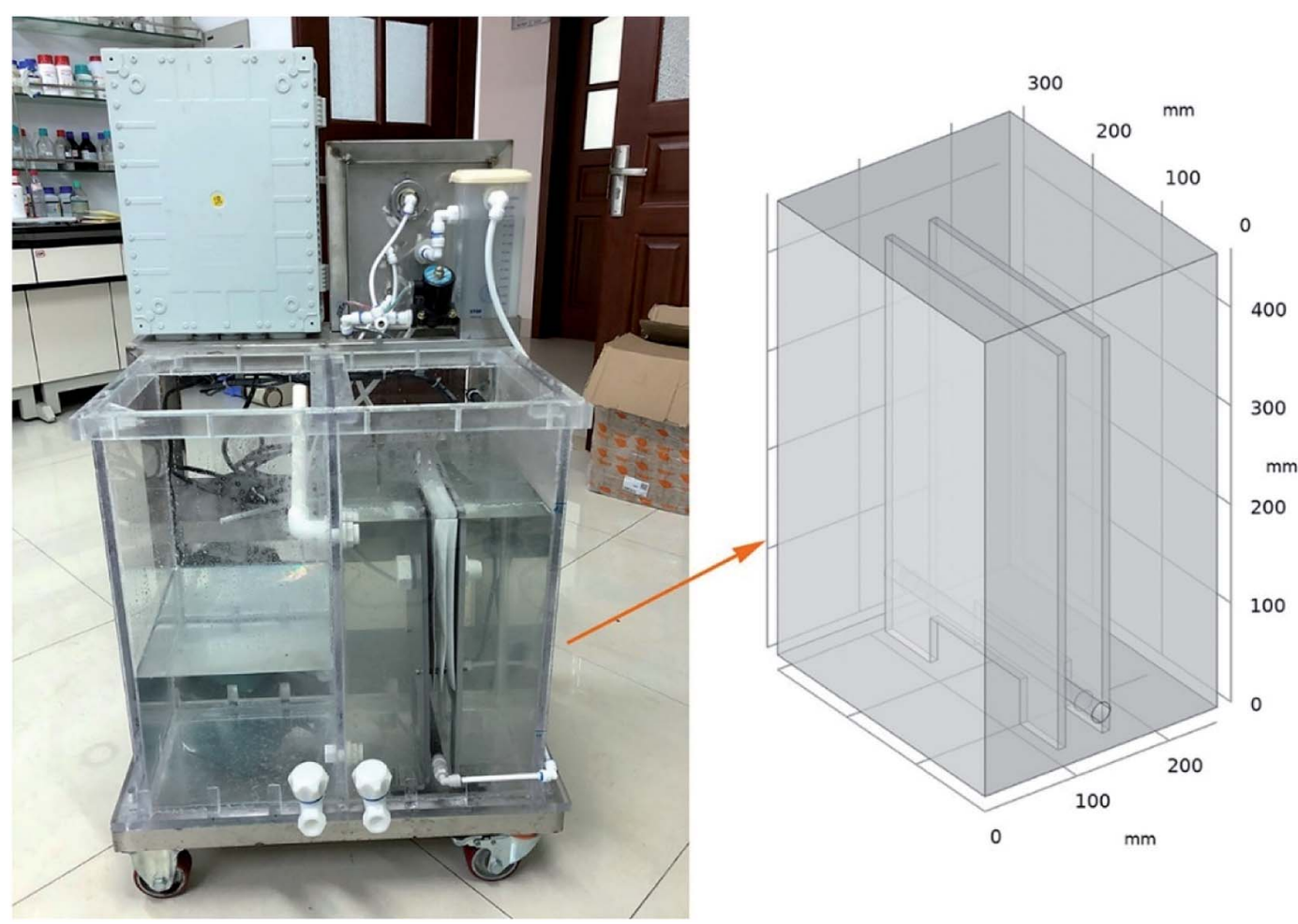

Fig. 2 Schematic of the experimental setup that was modeled in this study. 
model the motion of each bubble. Consequently, the focus of this study concentrated on modelling the macroscopic flow of the continuous phase, rather than the motion trajectories of individual bubbles. Therefore, a Eulerian model incorporating a standard $k$-epsilon analysis has been used to describe the turbulent flow of the fluid in the MBR. The complex fluid flow in the MBR means that not all factors could be calculated, and so the following simplifications were incorporated into the numerical model used:

(1) The material properties in the MBR remained unchanged throughout the analysis, with the liquid phase considered to be incompressible and conforming to Newtonian principles.

(2) No bubble coalescence or break-up was considered to occur, with bubble diameters remaining constant over the course of the simulation process.

(3) No mass exchange between the gas and liquid phases was considered to occur.

Base on these assumptions, the volume fractions of the gas and liquid phases in the Euler-Euler model used were set to $\varphi_{l}$ and $\varphi_{g}$, respectively. Continuity equations were developed independently for both phases, without the need to include an additional mass-transfer term. ${ }^{32}$

$$
\begin{gathered}
\frac{\partial\left(\phi_{k} \rho_{k}\right)}{\partial t}+\nabla\left(\phi_{k} \rho_{k} u_{k}\right)=0 \quad k=l, g \\
\varphi_{l}=1-\varphi_{g}
\end{gathered}
$$

Compared with turbulent viscous stress, the effect of molecular viscous stress on the two phases was considered to be negligible with the momentum equation written as follows. ${ }^{33}$

$$
\begin{aligned}
& \frac{\partial\left(\phi_{k} \rho_{k} u_{k}\right)}{\partial t}+\nabla\left(\phi_{k} \rho_{k} u_{k} u_{l}\right)=-\phi_{k} \nabla p+\nabla\left(\phi_{k} T_{k}^{\mathrm{turb}}\right)+\phi_{k} \rho_{k} g+F_{\mathrm{b}} \\
& \quad k=l, g
\end{aligned}
$$

where $u$ is velocity ( $\mathrm{m} \mathrm{s}^{-1}$ ), $p$ is pressure $(\mathrm{Pa}), \rho$ is density ( $\mathrm{kg}$ $\left.\mathrm{m}^{-3}\right), g$ is the gravity vector $\left(\mathrm{m} \mathrm{s}^{-2}\right), F_{\mathrm{b}}$ is the additional volume force $\left(\mathrm{N} \mathrm{m}^{-3}\right), T_{k}^{\text {turb }}$ is the turbulent stress tensor $\left(\mathrm{N} \mathrm{m}^{-3}\right)$.

The stress tensor used was described as follows:

$$
T_{k}^{\mathrm{turb}}=-\mu_{\mathrm{eff}, k}\left(\nabla u_{k}+\left(\nabla u_{k}\right)^{T}-\frac{2}{3} I\left(\nabla u_{k}\right)^{T}\right),
$$

where $\mu_{\mathrm{eff}, k}$ is the effective viscosity, and $I$ denote the identity tensor. For the liquid phase, the effective viscosity is the sum of the dynamic viscosity $\mu_{L, k}$ and the turbulent viscosity $\mu_{T, k}$,

$$
\mu_{\mathrm{eff}, k}=\mu_{L, k}+\mu_{T, k} .
$$

In this case, the turbulence properties, including the turbulent kinetic energy $k\left(\mathrm{~m}^{2} \mathrm{~s}^{-2}\right)$ and the dissipation rate of turbulent kinetic energy $\varepsilon\left(\mathrm{m} \mathrm{s}^{-3}\right)$ were solved using a multiphase $k-\varepsilon$ model.

Additional volume forces that act on the bubbles are drag forces, lift forces and virtual mass forces, however, the magnitude of the lift and virtual mass forces are relatively small in comparison to the drag forces. Díaz et $a .^{34}$ have shown that inclusion of virtual mass forces does not significantly effect calculations, whilst Sokolichin and Eigenberger ${ }^{32}$ have shown that inclusion of lift forces is not relevant without clear experimental evidence of their direction and magnitude. Therefore, only the effect of drag forces on the BMR model was considered in this study, with the drag force defined as,

$$
F_{\mathrm{D}}=-\frac{3}{4}\left(\phi_{g} \phi_{l} \rho_{l}\right) \frac{C_{\mathrm{D}}}{d_{\mathrm{b}}}\left|u_{l}-u_{g}\right|\left(u_{l}-u_{g}\right)
$$

where $d_{\mathrm{b}}$ is the bubble diameter $(\mathrm{m}), C_{\mathrm{D}}$ is the drag coefficient which was defined mathematically using semi-empirical methods. Evaluation of the drag coefficient required consideration of the bubble Reynolds number $\left(\operatorname{Re}_{\mathrm{b}}\right)$, whose value is based on the slip velocity of a single bubble in the fluid. Extensive results on drag coefficient values have been reported
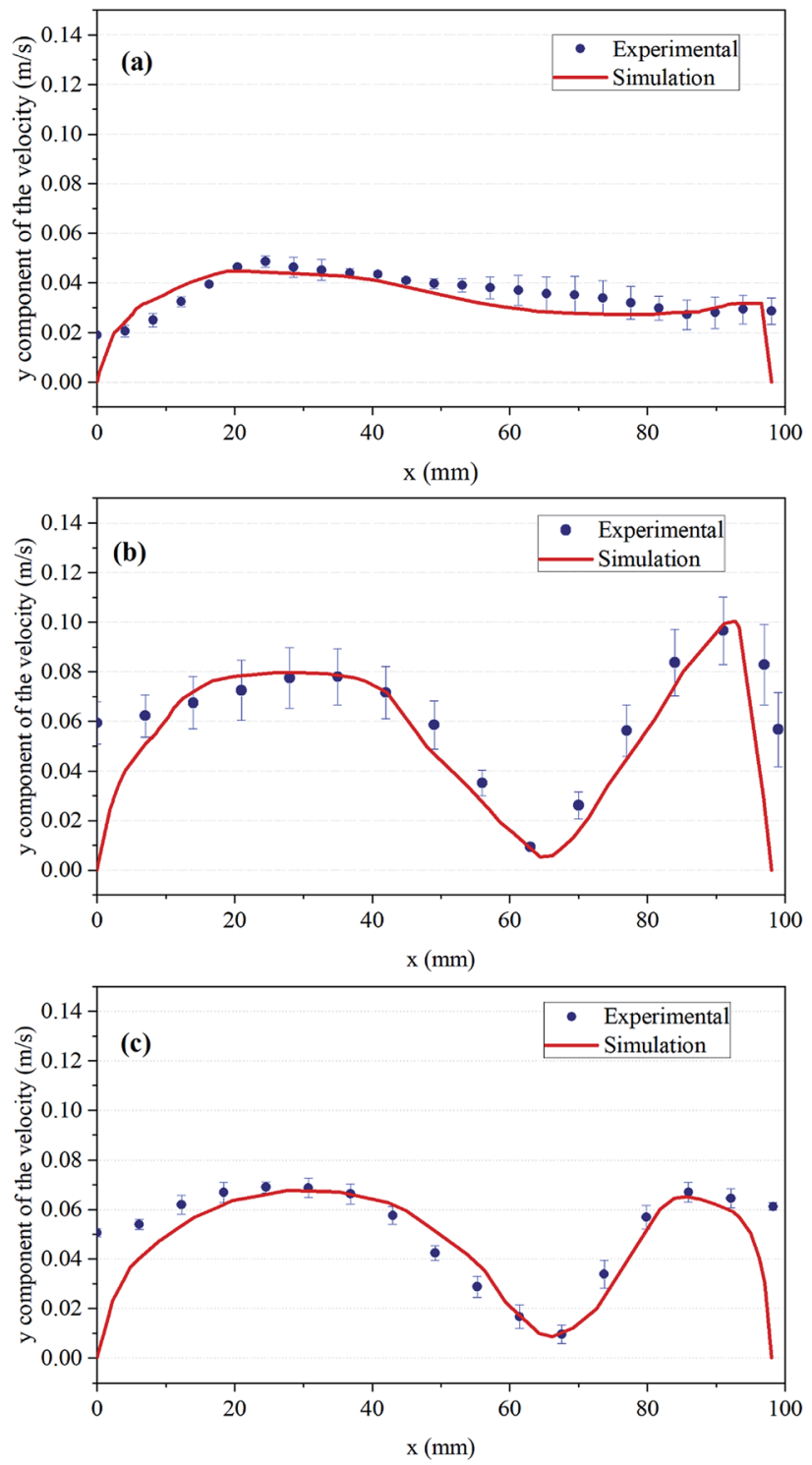

Fig. 3 Comparison of time-averaged velocities for different lines (generated using PIV techniques) with the mathematical model for aeration and liquid level heights of (a) $9 \mathrm{~L} \mathrm{~min}^{-1}, 50 \mathrm{~cm}$, (b) $3 \mathrm{~L} \mathrm{~min}$, $46 \mathrm{~cm}$, and (c) $15 \mathrm{~L} \mathrm{~min}^{-1}, 46 \mathrm{~cm}$. 


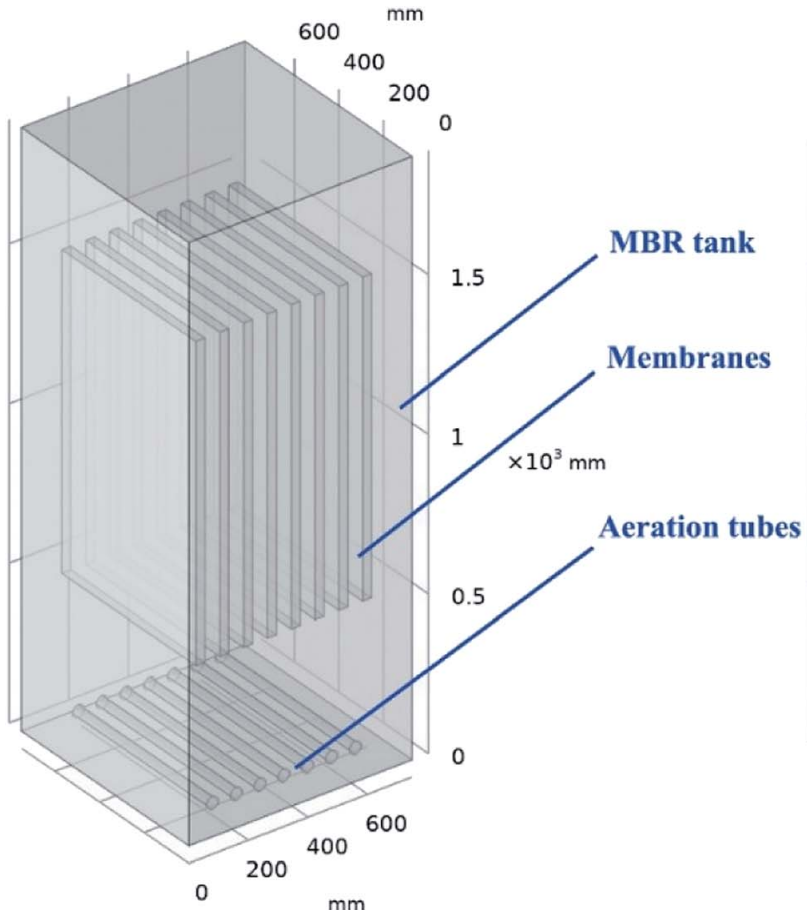

(a)

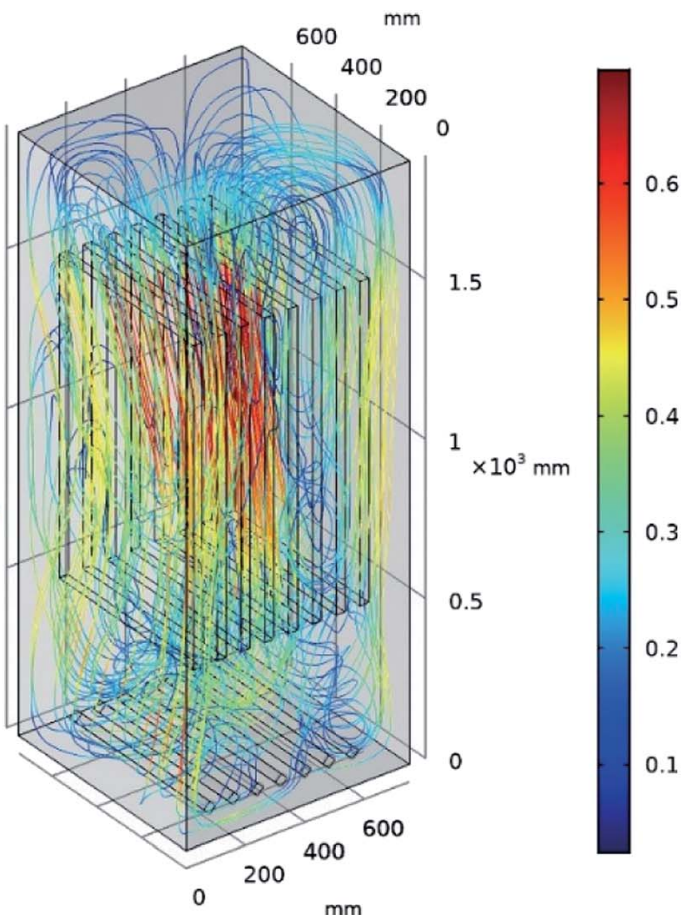

(b)

Fig. 4 Schematic diagram of MBR and the streamline and velocity (color legend) of the liquid phase in the MBR.

in the literature, with the drag coefficient reported by Schiller and Naumann used as the basis for our calculations:

$$
\begin{aligned}
& C_{\mathrm{D}}=\left\{\begin{array}{cc}
\frac{24}{\mathrm{Re}_{\mathrm{b}}}\left(1+0.15 \mathrm{Re}^{0.687}\right) & \mathrm{Re}_{\mathrm{b}} \leq 1000 \\
0.44 & \mathrm{Re}_{\mathrm{b}}>1000
\end{array}\right. \\
& \operatorname{Re}_{\mathrm{b}}=\frac{d_{\mathrm{b}} \rho_{l}\left|u_{l}-u_{g}\right|}{\mu_{l}},
\end{aligned}
$$

These equations were solved using the COMSOL Multiphysics software package using a time-dependent mode, with solutions calculated using a backward differential (BDF) method with an order of 2 . The initial step size and the maximum solution step size were both set to $10^{-4} \mathrm{~s}$, with each step of the solution having an absolute tolerance level of
$10^{-5}$. Flow field and gas content distribution levels were found to stabilize after a calculation time of $100 \mathrm{~s}$, with a "timeavg" function then used to average global results in the last $10 \mathrm{~s}$.

\section{Simulation validation}

It was necessary to validate the accuracy of the mathematical models before using them to analyse real systems, with the models developed in this report validated using flow field data generated using PIV techniques.

\subsection{Grid independence}

The quality of the simulation results was confirmed using grid independence tests to determine the effect of the grid

Table 1 Structural parameters of the membrane bioreactor

\begin{tabular}{lc}
\hline Definition & Parameters \\
\hline Number of membranes & 8 \\
Number of aeration tubes & 7 \\
Dimensions of MBR & $750 \mathrm{~mm} \times 750 \mathrm{~mm} \times 1890 \mathrm{~mm}$ \\
Dimensions of membrane & $600 \mathrm{~mm} \times 30 \mathrm{~mm} \times 1015 \mathrm{~mm}$ \\
Distance of membrane & $80 \mathrm{~mm}$ \\
Distance of aeration tube & $80 \mathrm{~mm}$ \\
Distance from membrane to bottom of & $450 \mathrm{~mm}$ \\
tank & $375 \mathrm{~mm}$
\end{tabular}


size. An unstructured tetrahedral grid was used in the model, with the grid size being reduced from $250 \mathrm{~mm}$ to $60 \mathrm{~mm}$ and the corresponding grid numbers increased from $3.6 \times 10^{3}$ to $1.8 \times 10^{4}$.

As shown in Fig. 1, the MBR numerical model reveals that different grid sizes produce large differences in fluid flow rates, with velocity distribution points tending to be stable for grid sizes between 20 and $25 \mathrm{~mm}$. As a result, an unstructured
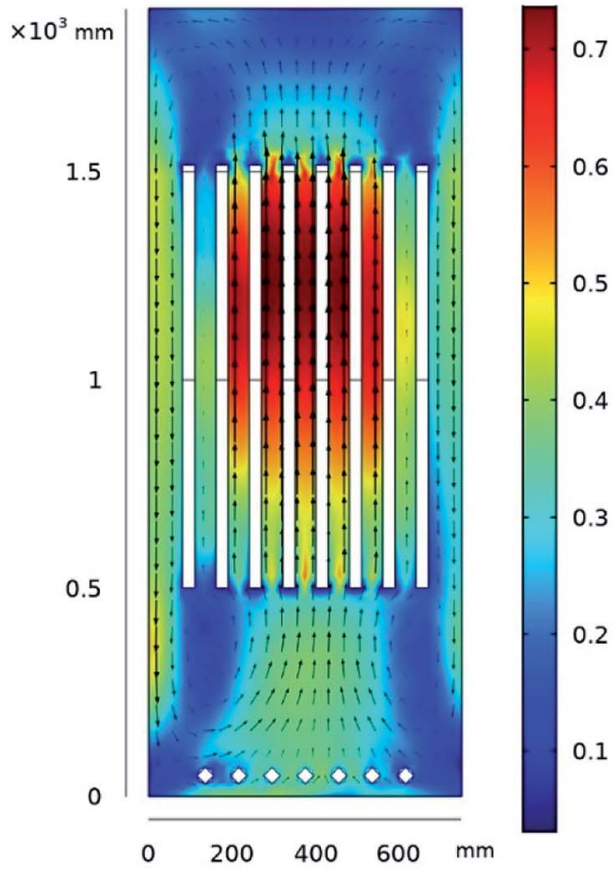

(a)

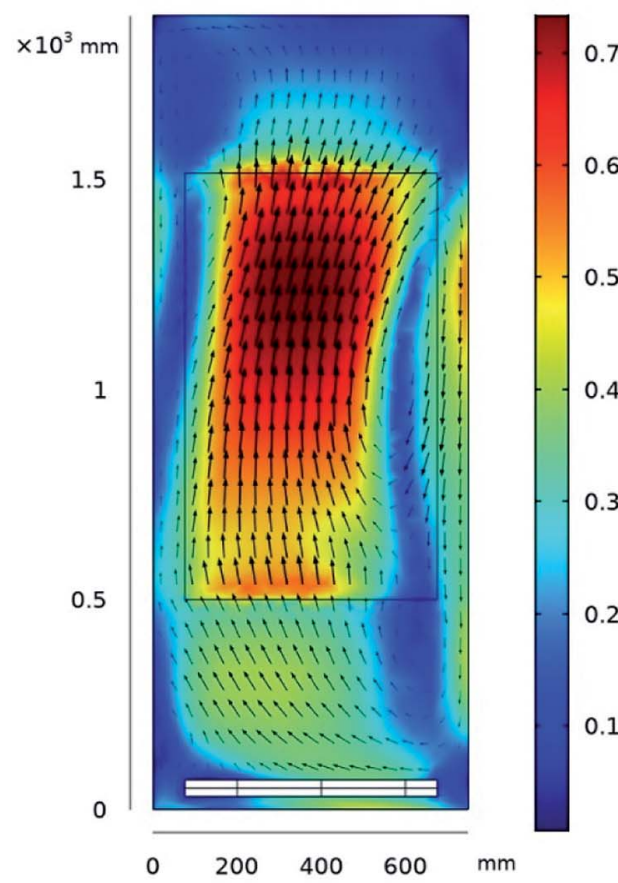

(c) tetrahedral grid size of $25 \mathrm{~mm}$ was selected for all subsequent simulations, which generated acceptable accuracy levels for manageable computational times.

\subsection{PIV experiments}

Numerical accuracy levels were verified using a cold model of MBR with aeration and liquid level heights of $9 \mathrm{~L} \min ^{-1}$ and

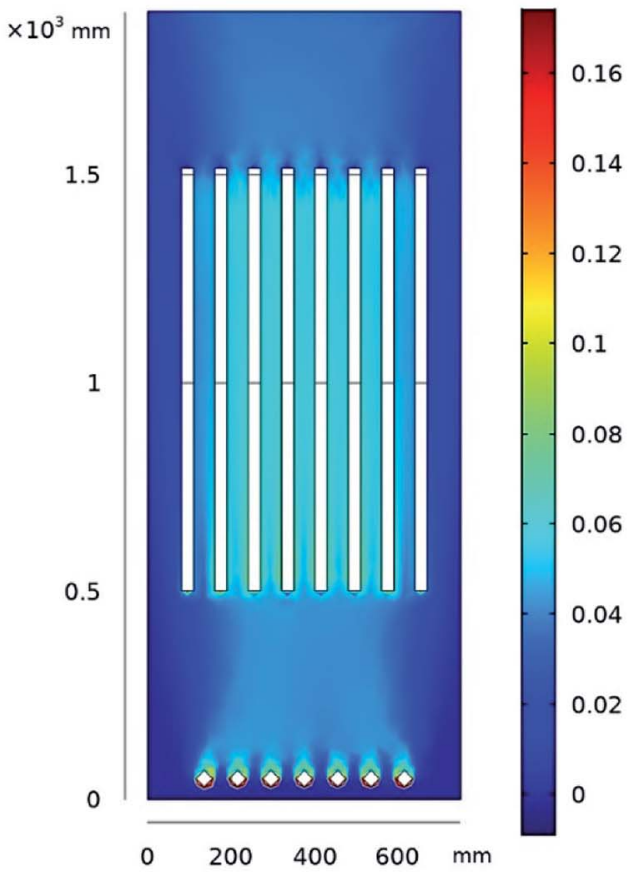

(b)

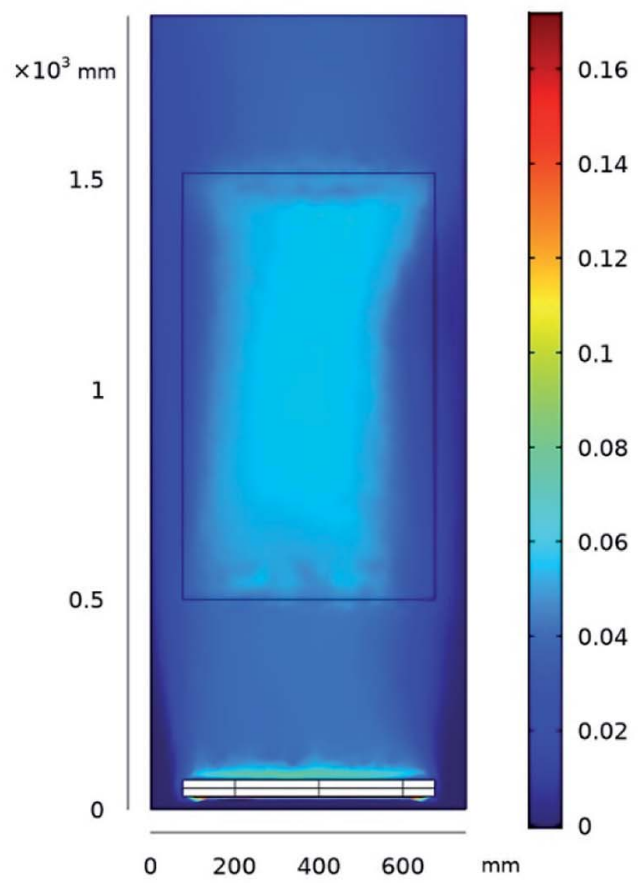

(d)

Fig. 5 Distribution of mean liquid phase velocities and gas volume fractions for $y=400 \mathrm{~mm}$ and $x=400 \mathrm{~mm}$. (a) liquid phase velocities for $y=$ $400 \mathrm{~mm}$; (b) gas volume fractions for $y=400 \mathrm{~mm}$; (c) liquid phase velocities for $x=400 \mathrm{~mm}$; (d) gas volume fractions for $x=400 \mathrm{~mm}$. 
$50 \mathrm{~cm}$ and $3 \mathrm{~L} \mathrm{~min}^{-1}$ and $46 \mathrm{~cm}, 15 \mathrm{~L} \mathrm{~min}^{-1}$, respectively. Liquid phase velocity distributions were compared for a range of $x=0$ $98 \mathrm{~mm}, y=150 \mathrm{~mm}$ and $z=375 \mathrm{~mm}$. The equipment and the corresponding model used for simulation experiments are shown in Fig. 2, with fluid motions measured using PIV techniques. The PIV measurement was conducted using a double pulsed Nd:YAG laser of $532 \mathrm{~nm}$ wavelength, and maximum energy of $100 \mathrm{~mJ}$ per pulse (Continuum Inc., USA). The laser beam was passed through an optical arrangement consisting of cylindrical and spherical lenses, which generated a laser sheet with a thickness of $1 \mathrm{~mm}$. The images were acquired by a single frame-straddling digital CCD camera (PowerView Plus, TSI Inc., USA) at a resolution of $2048 \times 2048$ pixels, which was positioned perpendicular to the plane of the light sheet in the glass tank. Frame and laser sequencing were controlled by a Laser pulse 610035 synchronizer (TSI Inc., USA). For all images processing in TSI Insight $4 \mathrm{G}$ software, the interrogation area (IA) was $64 \times 64$ pixels, with $50 \%$ overlap. A range filter was implemented to the raw data to remove obvious spurious vectors. The flow characteristics of gas-liquid two-phase flow in this MBR study were instantaneous, with error curves determined for 500 PIV images (three times averaged) for each set of experimental conditions.

The results of this modelling study are shown in Fig. 3, with the flow rates generated from experimental and calculated showing large gaps at two sides of the membrane wall (boundary condition set at $u=0 \mathrm{~m} \mathrm{~s}^{-1}$ ). The velocity distribution of the wall boundary could not be measured experimentally, however modelling predictions agreed well with previously determined experimental values, thus indicating that the numerical model has good reliability over the flow range tested.
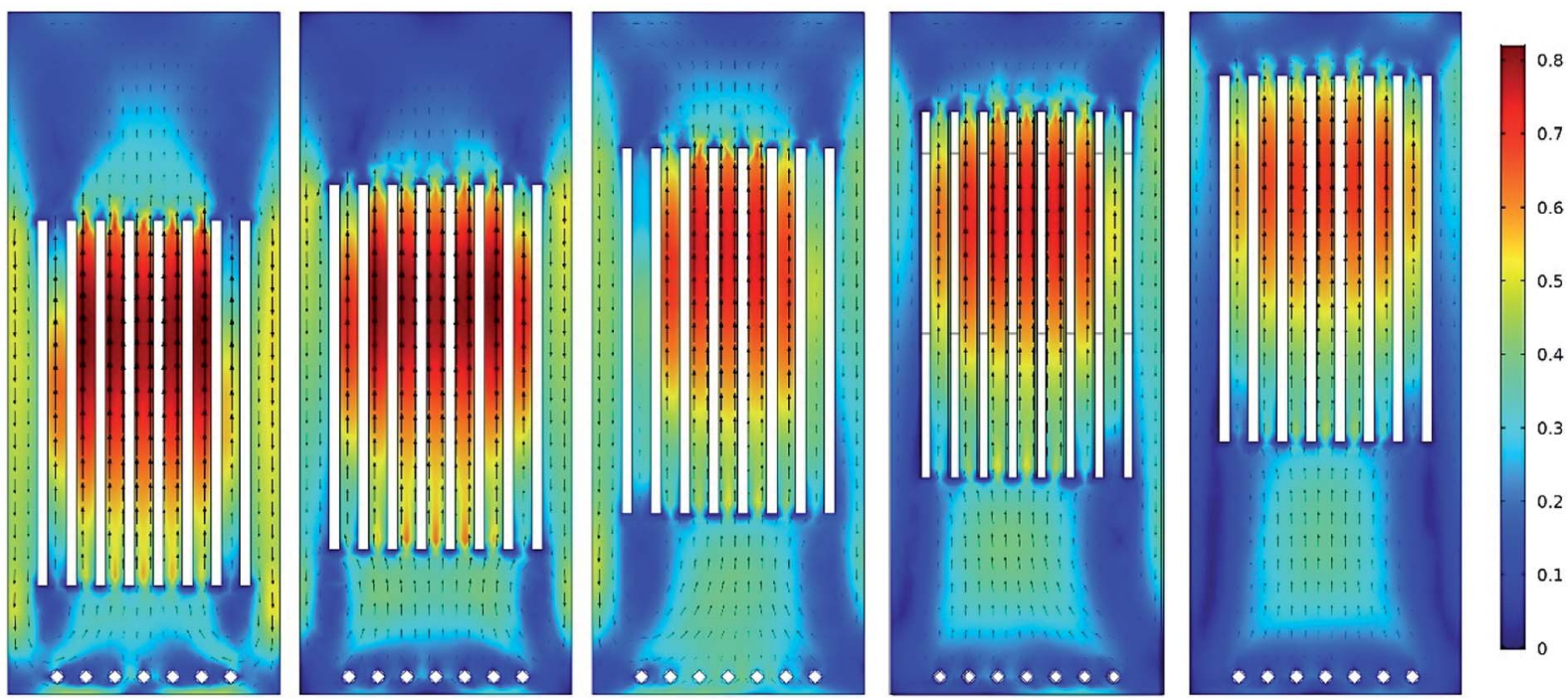

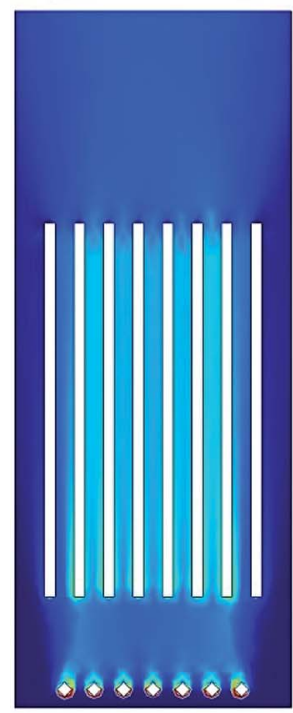

(a)

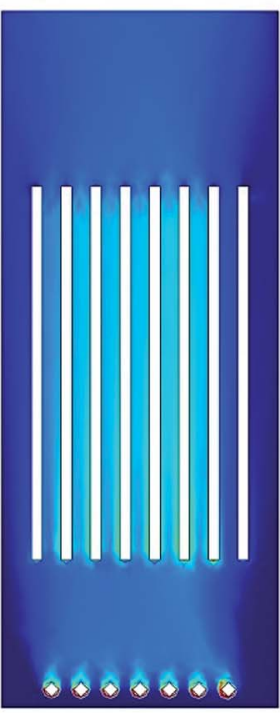

(b)

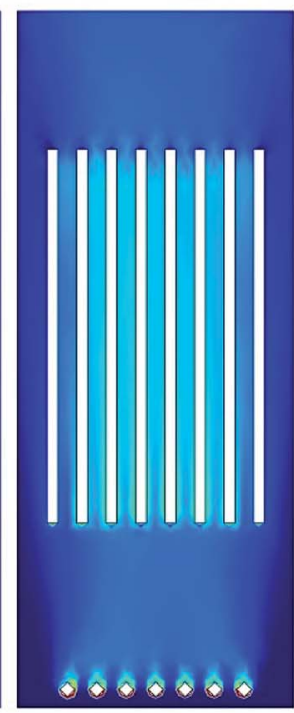

(c)

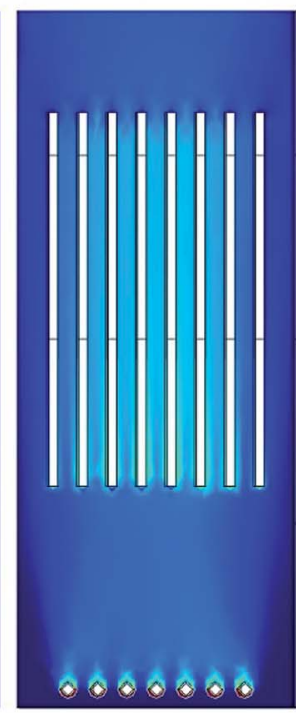

(d)

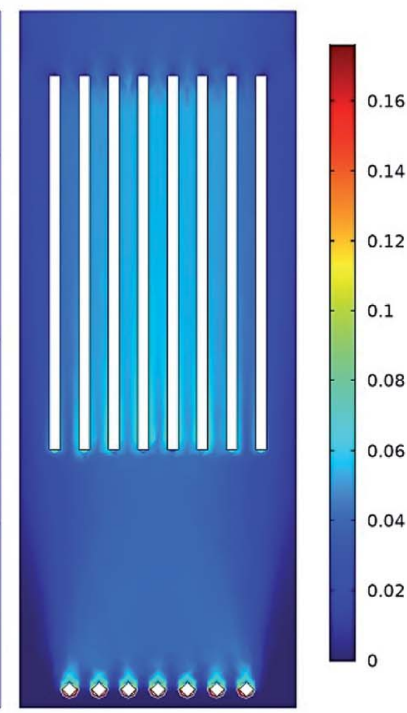

(e)

Fig. 6 Distribution of mean liquid phase velocities and gas volume fractions at $y=400 \mathrm{~mm}$ planes for different membrane module heights: (a) $250 \mathrm{~mm}$; (b) $350 \mathrm{~mm}$; (c) $450 \mathrm{~mm}$; (d) $550 \mathrm{~mm}$; (e) $650 \mathrm{~mm}$. 


\section{Results and discussion}

\subsection{Experimental apparatus}

MBRs are usually prepared from the combination of membranes sheets which simplifies their industrial production, with this paper employing CFD studies to model fluid dynamics of this type of MBR fitted with a series of aeration tubes in a membrane tank filled with aqueous media (see Fig. 4). The geometrical dimensions of the computed model were established according to the structure of the MBRs that were available, whose detailed structural parameters are reported in Table 1.

\subsection{Hydrodynamic characteristics of the MBR}

The densities and viscosities of the bubbles and water in the system were set at $1.22 \mathrm{~kg} \mathrm{~m}^{-3}$ and $1.75 \times 10^{-5} \mathrm{~kg} \mathrm{~m}^{-1} \mathrm{~s}^{-1}$, and $998.06 \mathrm{~kg} \mathrm{~m}^{-3}$ and $1.00 \times 10^{-3} \mathrm{~kg} \mathrm{~m}^{-1} \mathrm{~s}^{-1}$, respectively. The initial conditions used to generate the MBR model were: (e)

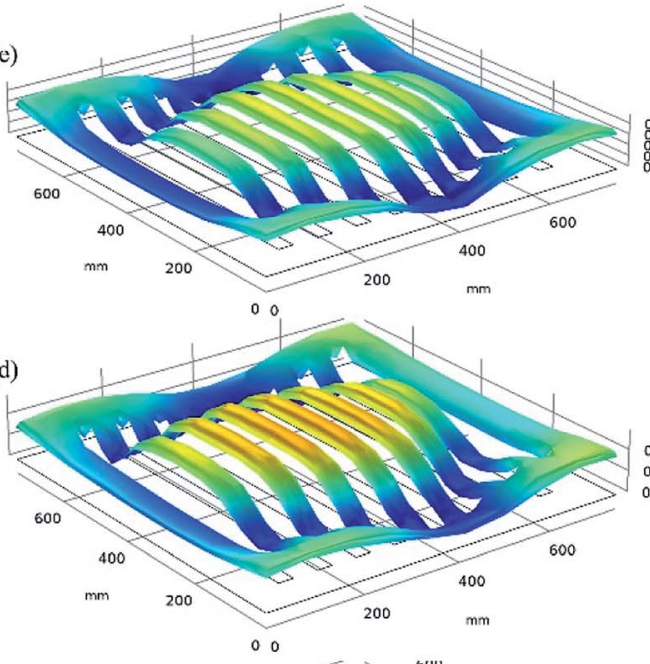

(c)

(b)

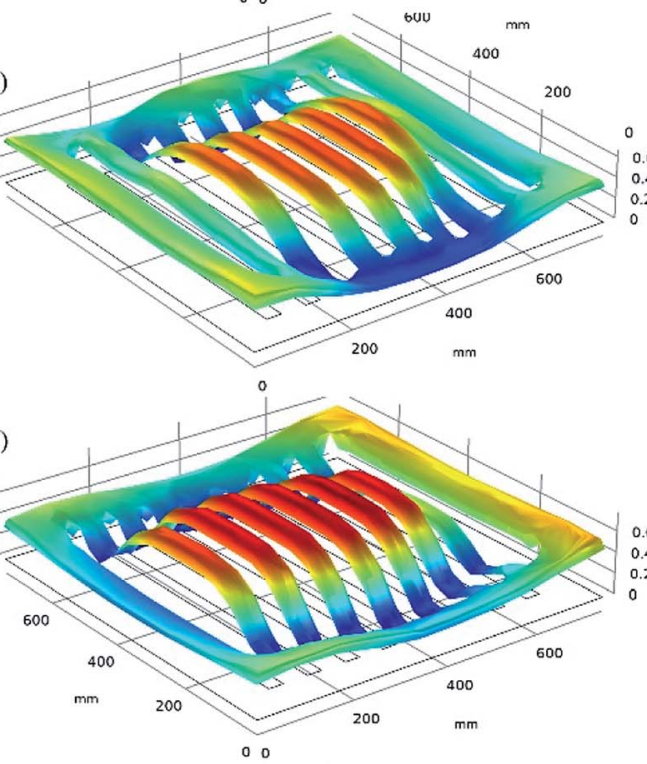

(a)

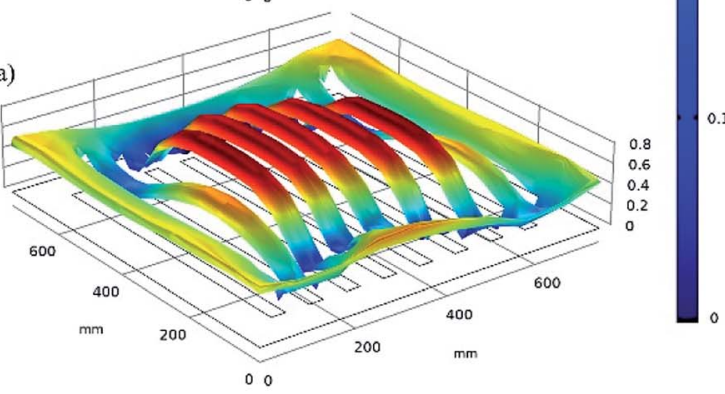

0.7 0.4
0.2
0

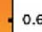

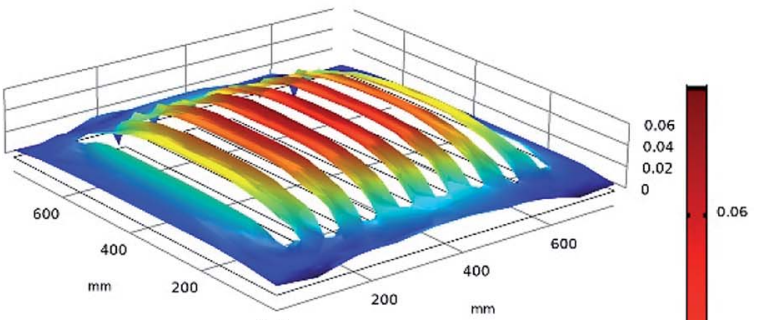

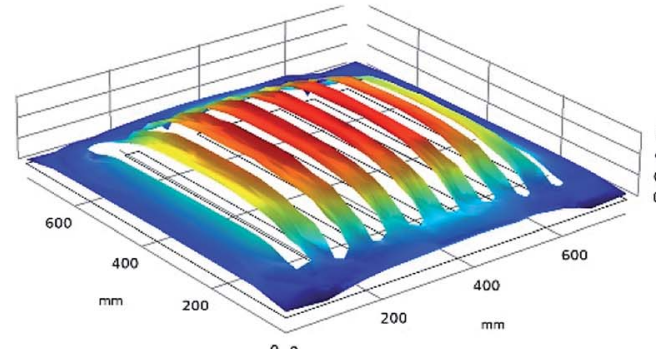

0.05

0.5

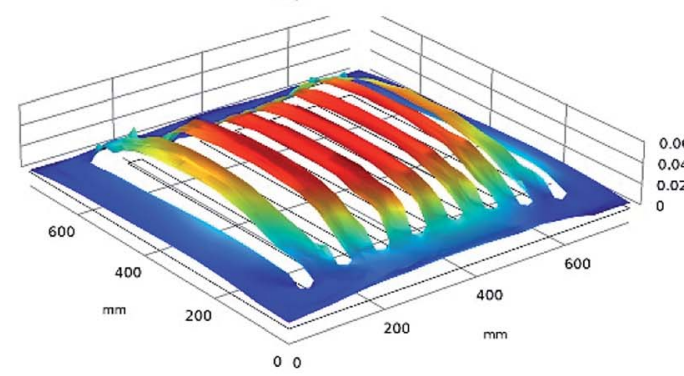

0.04

0.03
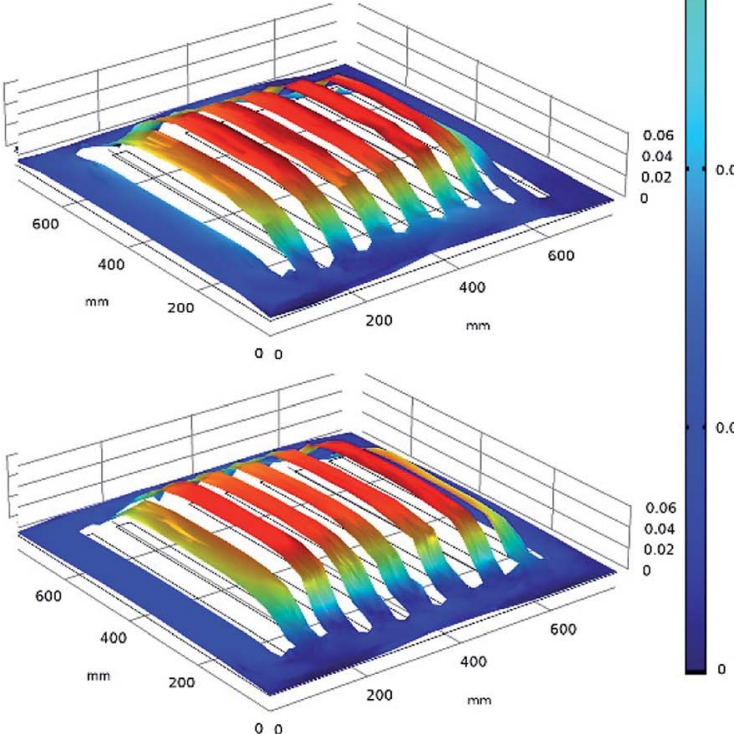

Fig. 7 Distribution of mean liquid phase velocities and gas volume fractions at $z=1000 \mathrm{~mm}$ with different membrane module heights of: (a) 250 $\mathrm{mm}$; (b) $350 \mathrm{~mm}$; (c) $450 \mathrm{~mm}$; (d) $550 \mathrm{~mm}$; (e) $650 \mathrm{~mm}$ 
aeration volume of $1.7 \mathrm{~m}^{3} \mathrm{~min}^{-1}$, bubble size of $1 \mathrm{~mm}$, membrane module height of $450 \mathrm{~mm}, 7$ aeration tubes, with membrane spacings of $5 \mathrm{~mm}$. The overall state of the liquid flowing throughout the MBR is shown in Fig. 4.

Fig. 5(a) shows the distribution of the mean liquid phase velocities and gas volumes fraction in the center section $(y=$ 400) of the MBR reactor, which reveals a maximum flow rate of $0.74 \mathrm{~m} \mathrm{~s}^{-1}$ in the centers of the channels between the membranes. The fluid flows from the channel to the liquid surface from the left and right sides of the membrane plate, forming two left and right cycles at their cross-section. Similar velocity profiles are obtained by the experiments of Liu et al. ${ }^{35}$ Fig. 5(b) shows a cloud plot of the average gas holdup distribution at the same position in the MBR reactor, with bubbles accumulating at the lower edge of the aeration tube with a gas content of up to $17 \%$. The gas phase (with a gas content of around $5 \%$ ) is evenly distributed between the membrane plates, with Fig. 5(c) and (d) showing the average velocity and average gas fraction distribution in the side section $(x=400)$ of the MBR. In addition to the aeration tubes, the gas holdup is mainly concentrated between the membrane plates, with gas holdup rates lower and unevenly distributed in other places. The distribution of gas content on both sides of the module is relatively low, which is not ideal for washing precipitated pollutants away from the surface of the membrane to prevent its blocking.

\subsection{Effect of membrane module height on performance}

Bubbles fare generated from the aeration tube and float up to the liquid surface, where they gradually disperse to form a feather-like shapes, with the membrane module structure having a significant effect on gas-liquid mixing efficiency and fluid circulation dynamics. ${ }^{36}$ Therefore, the height of the arrangement of the membrane modules is an important factor determining gas holdup and fluid flow, which led us to investigate the effect of varying the height of the membrane from $250 \mathrm{~mm}$ to $650 \mathrm{~mm}$, for an aeration volume of $1.7 \mathrm{~m}^{3} \mathrm{~min}^{-1}$. The average velocity distributions determined for different membrane heights at the $y=400 \mathrm{~mm}$ plane are shown in Fig. 6, which shows that the liquid phase passes through the channel between the membrane plates, before flowing down from the outside of the membrane plate. The average flow rates after stabilization were found to be $0.299,0.293,0.287,0.260$ and $0.238 \mathrm{~m} \mathrm{~s}^{-1}$, respectively. As the distance increased, the overall liquid phase flow rates decreased, with the highest flow velocities between the membranes showing a downward trend of $0.795,0.827$, $0.739,0.728$ and $0.691 \mathrm{~m} \mathrm{~s}^{-1}$, respectively. As the distance from the membrane module to the aeration tube increases, more fluid flows from the periphery of the membrane plate, ultimately causing a decrease in flow rate between the membrane plates.

Fig. 6 shows the average gas holdup distribution for different membrane heights at the $y=400 \mathrm{~mm}$ plane, with gas distribution in the membrane channels in the five structures found to be relatively uniform. However, the gas volume fraction gradually increased with an increase in the height of the membrane, meaning that more bubbles rise directly from the periphery of the membrane to the liquid surface. Fig. 7 shows the average liquid phase velocity distribution and the average gas-capacity distribution cloud map for the $x-y$ plane at $z=$ $1000 \mathrm{~mm}$, with fluid flowing mainly through the central passage of the diaphragm, with a low velocity in the peripheral passage of the diaphragm. These modelling studies also revealed that the flow velocity distributions between each channel were uneven and that there was a velocity gradient in each channel, with the liquid flow rate between membrane plates decreasing as the distance between them increased. The gas phase was essentially the same for all five structural types which were evenly distributed between the membrane sheets.

Fig. 8 shows the average, maximum and minimum values of shear stresses on the membrane surface, with average shear stresses after stabilization equal to $0.150,0.141,0.133,0.128$ and 0.119 Pa, respectively. Average shear stress values of the membrane assemblies were found to gradually decrease for an increasing distance from their aeration tube. This indicates that shorter distance between the membrane assembly and the aeration tube are favored in order to maximize erosion effects that minimize membrane fouling. Liu et al. ${ }^{15}$ found that the shear stress grew not significantly with the distance extended from $150 \mathrm{~mm}$ to $300 \mathrm{~mm}$.

\subsection{Effect of the number of aeration tubes on membrane performance}

Results on the effect of the height of the membrane modules revealed that the flow field passes primarily through the most central membrane channel of the membrane module. This means that the number and placement position of aeration tubes in the MBR will have a significant effect on fluid flow. Liu et $a l .{ }^{15}$ observed that the water velocity contour

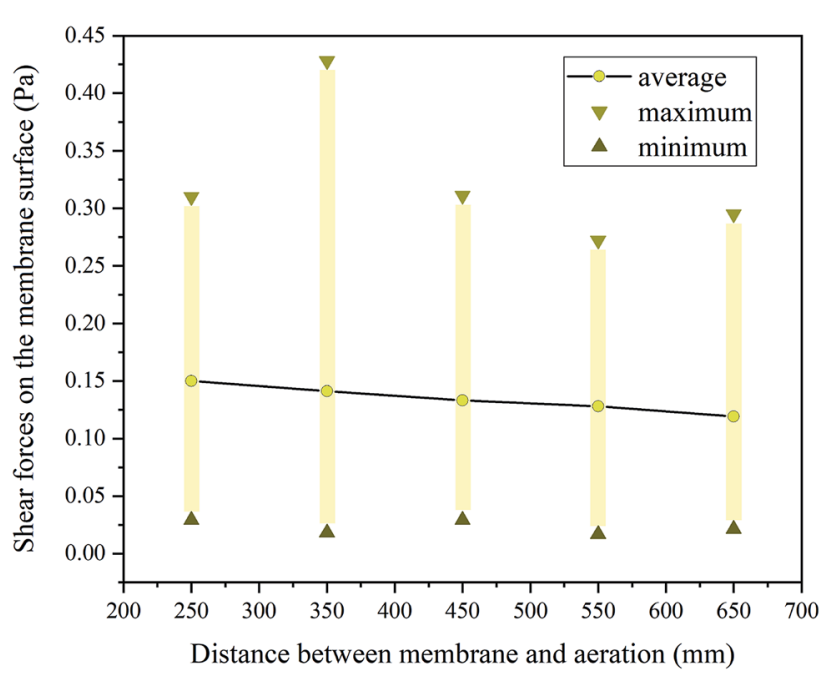

Fig. 8 Shear stress on membrane surfaces for different membrane module heights. 

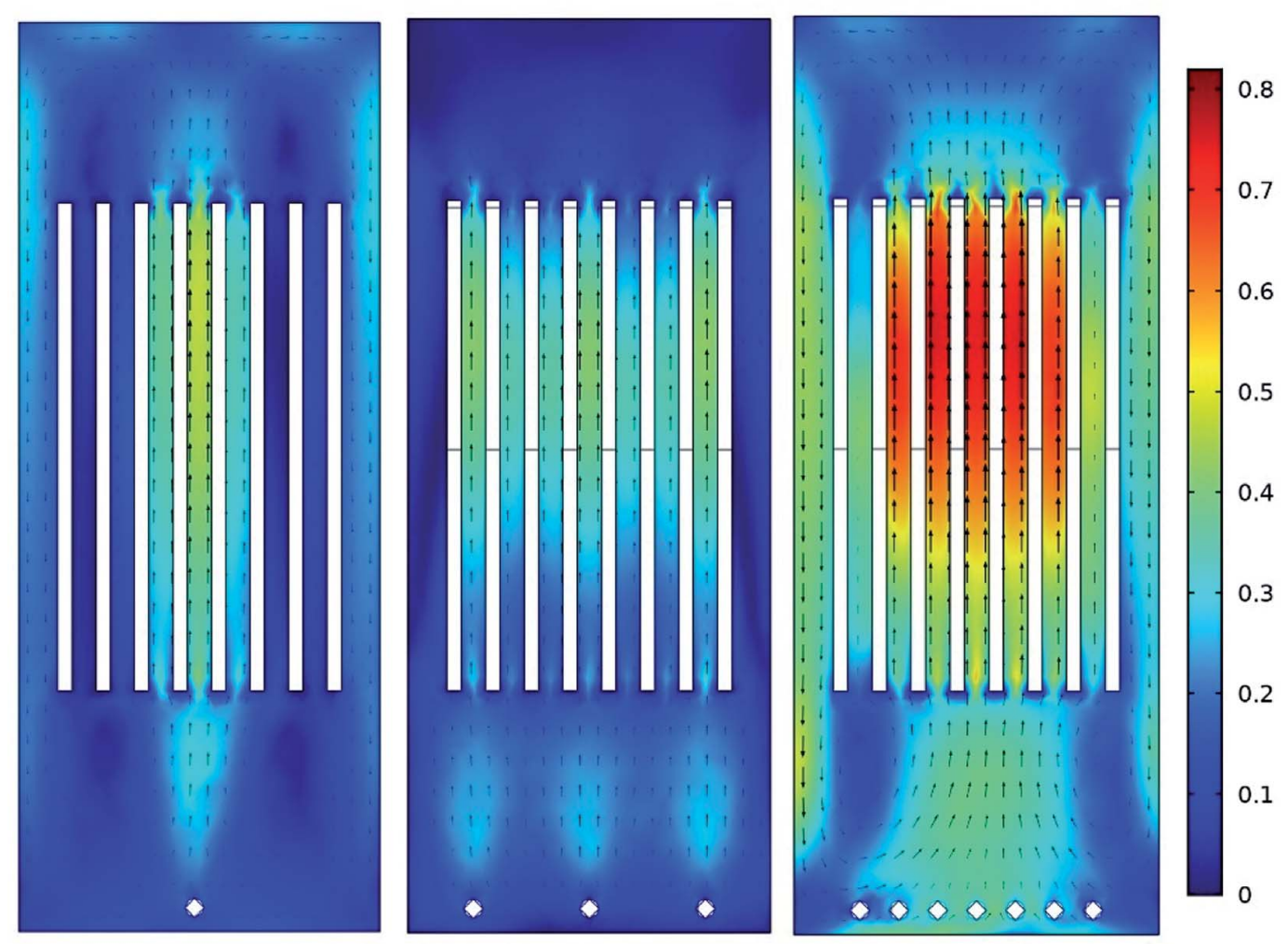

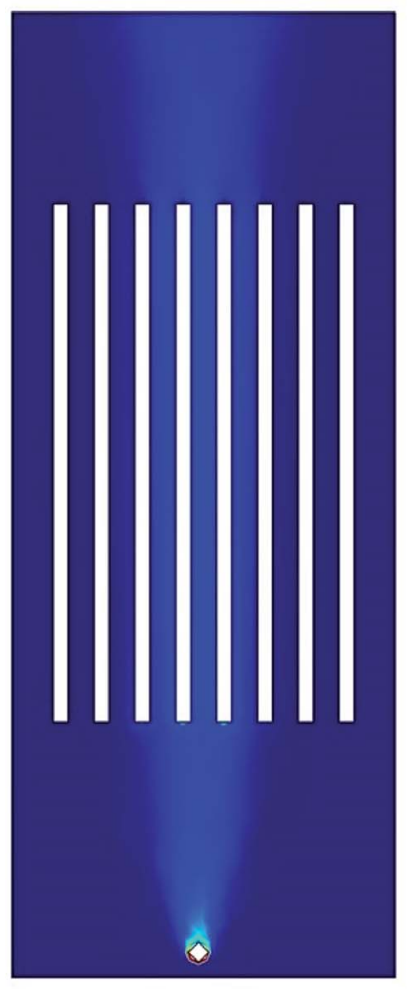

(a)

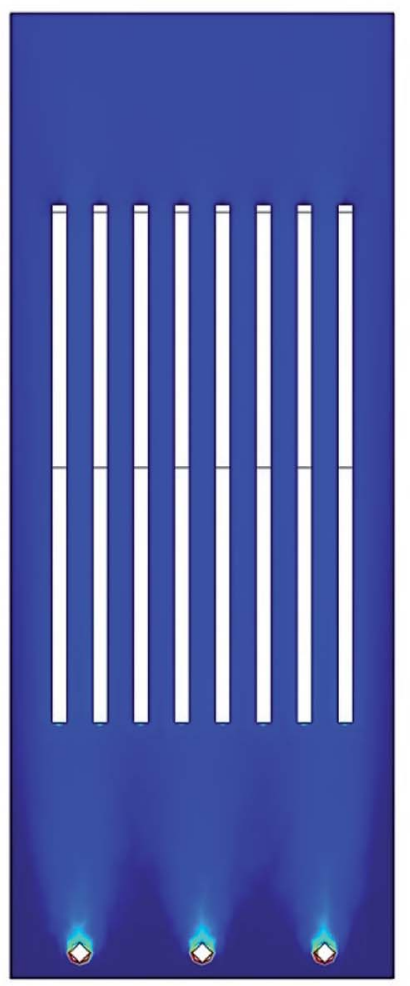

(b)

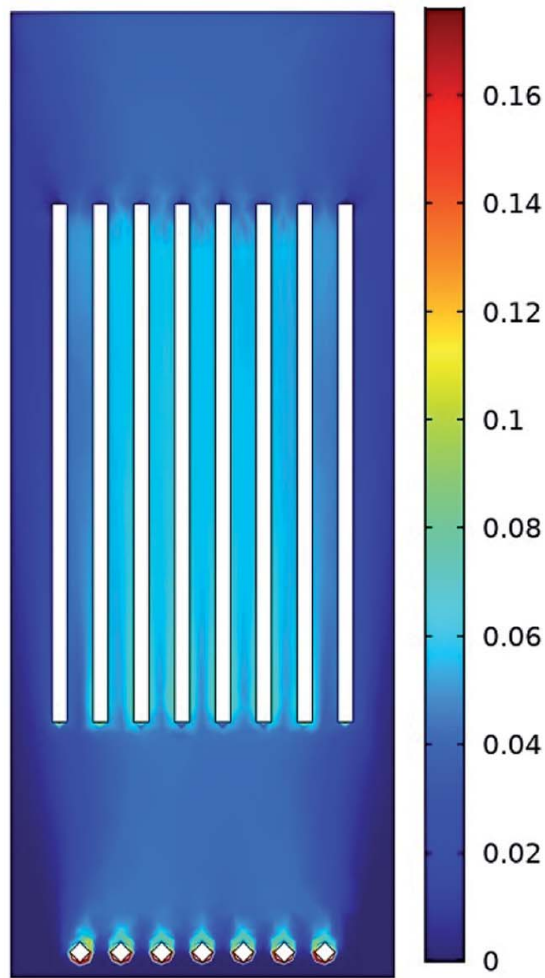

(c)

Fig. 9 Distribution of mean liquid phase velocities and gas volume fraction for different numbers of aerating tubes: (a) 1; (b) 3; (c) 7.

distributed in parallel arrangements (pipes under the Therefore, the model with the performance of MBRs conmembranes and between adjacent membranes) was much taining aeration tube numbers of 1,3 and 7 investigated for more even than that of perpendicular arrangement. a gas flow rate of $1.7 \mathrm{~m}^{3} \mathrm{~min}^{-1}$. 


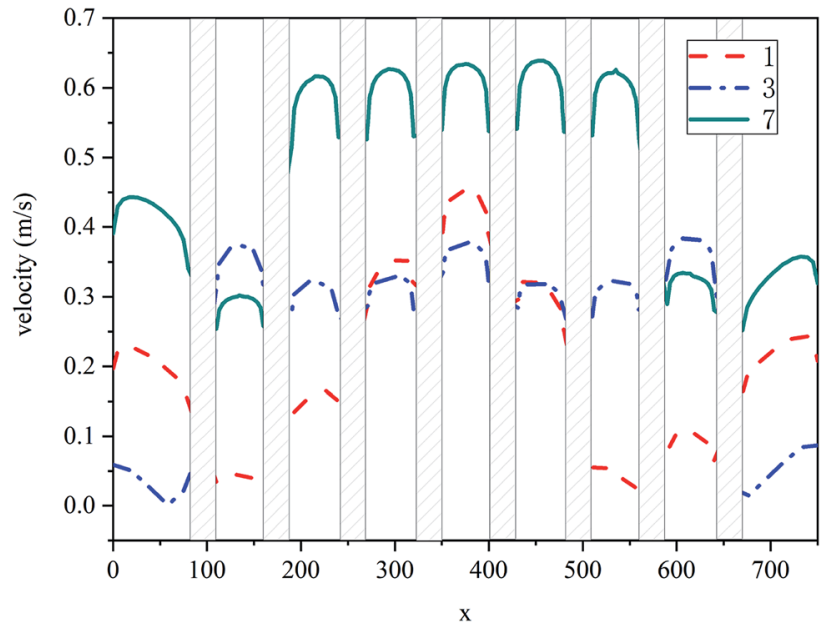

Fig. 10 Mean liquid phase velocity distributions at $y=375 \mathrm{~mm}$ and $z=$ $1000 \mathrm{~mm}$ for different numbers of aerating tubes.

Distributions of mean liquid phase velocities and gas volume fractions for different numbers of aeration tubes on the $y=400 \mathrm{~mm}$ plane are shown in Fig. 9. The average flow

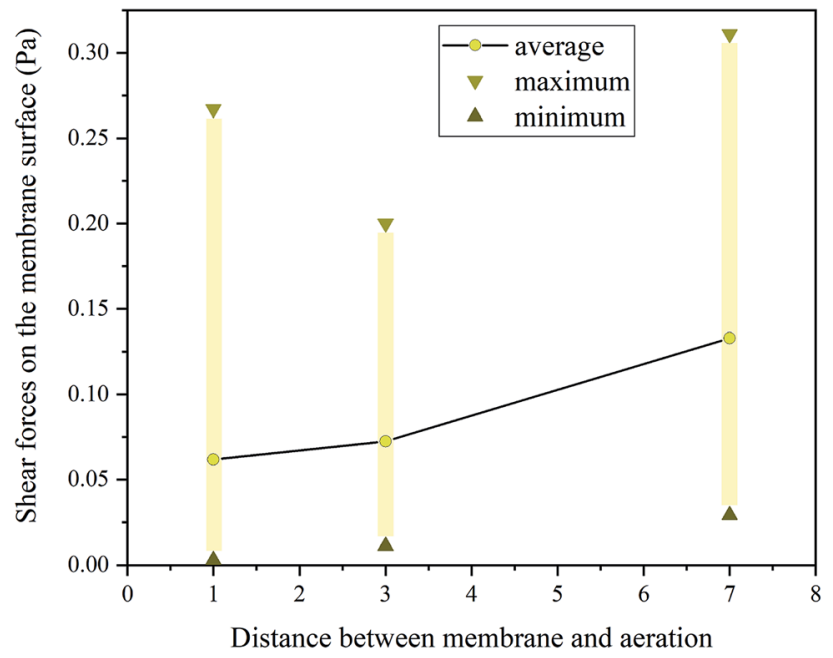

Fig. 12 Shear stress at membrane surfaces for different numbers of aerating tubes.

rates after stabilization were $0.155,0.162$ and $0.287 \mathrm{~m} \mathrm{~s}^{-1}$, respectively, which indicates that the overall flow rate of the liquid phase for multiple aeration tubes is increased. The
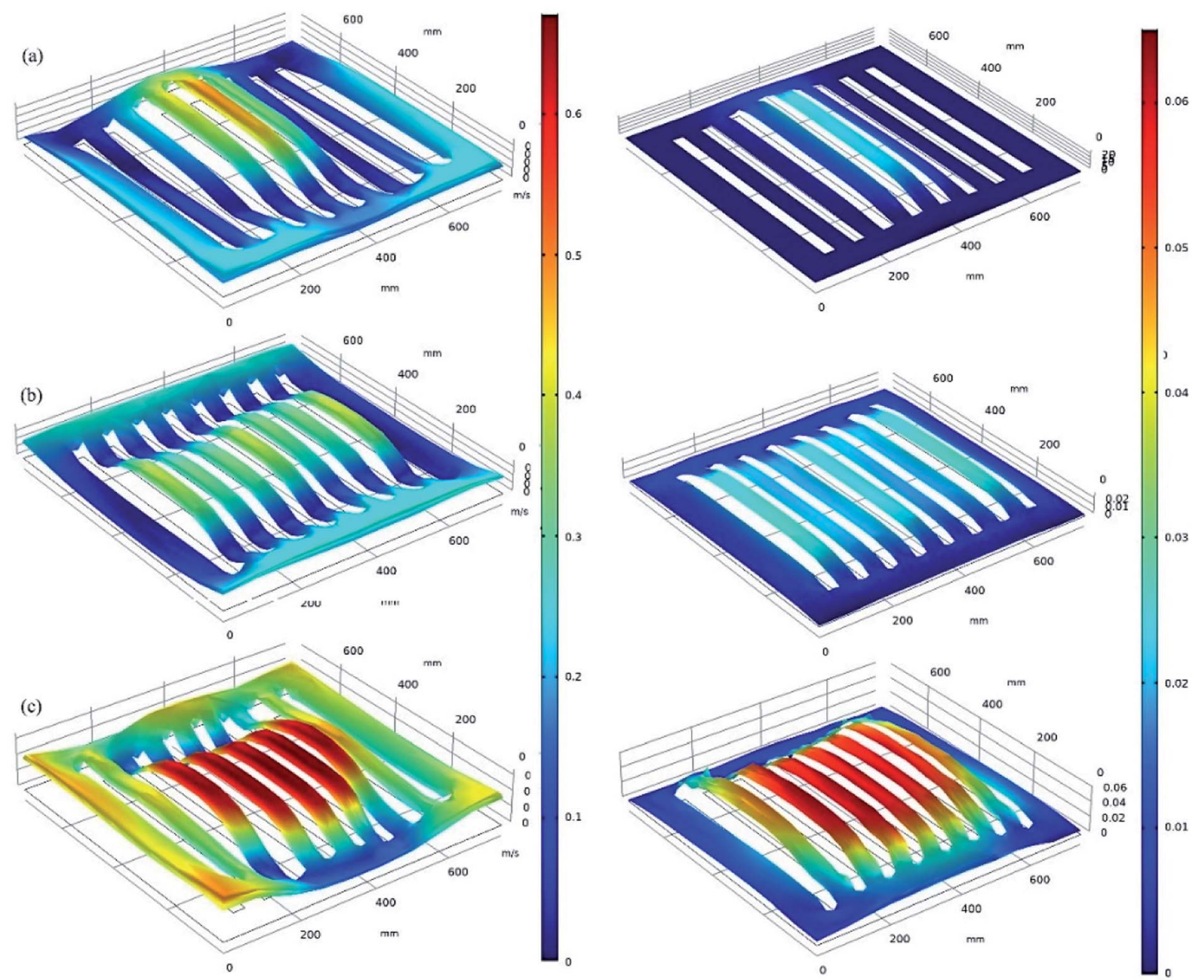

Fig. 11 Distribution of mean liquid phase velocities and gas volume fractions at $z=1000 \mathrm{~mm}$ for different numbers of aerator tubes: (a) 1 ; (b) 3; (c) 7 . 
highest flow velocities between the membranes showed a downward trend of $0.617,0.451$ and $0.738 \mathrm{~m} \mathrm{~s}^{-1}$, respectively. A reactor fitted with a single aeration tube results in gas being concentrated in the channel directly above the aeration tube, whilst use of three aeration tubes results in a more uniform flow velocity distribution between the channels. The average gas holdup of the three models investigated was $0.35 \%, 1.25 \%$, and $2.66 \%$, respectively, with the gas content in the MBR gradually increasing and becoming more uniformly distributed as the number of aeration tubes increased.

Fig. 10 shows the velocity profile at the MBR centerline $(y$ $=375 \mathrm{~mm}$ and $z=1000 \mathrm{~mm}$ ), with 7 aeration tubes affording a higher velocity in almost every channel, three aeration tubes giving the most uniform flow velocity distribution; and one aeration tube resulting in the greatest differences in flow velocities between channels.

The distribution of mean liquid phase velocities and gas volume fractions for different numbers of aerating tubes at $z$ $=1000 \mathrm{~mm}$ is shown in Fig. 11, with their liquid phases flowing mainly from the center of the membrane plate, with low flow velocities in the peripheral passage of the membrane module. The flow velocity was higher in the middle of the channel, while a boundary layer with much lower velocity existed near the membrane surface. The nonuniformity of gas-liquid flow in channels between two membranes was also found by Zhang et al. ${ }^{11}$ Fluid flowed through the central member channel of the MBR fitted with only one aeration tube, thus indicating that flow velocity distribution between the channels was non-uniform and that significant velocity gradients were present. However, the gas content in the MBR fitted with seven aeration tubes was much higher are more uniformly distributed, indicating a more optimal design.

Fig. 12 shows the average, maximum, and minimum shear stress values at the membrane surface for aeration tube numbers of 1,3 , and 7 , respectively, with average values after stabilization increasing from 0.062 through 0.072 to $0.133 \mathrm{~Pa}$, respectively.

\subsection{Effect of membrane spacing}

Membrane spacing is an important factor affecting fluid flow between membrane sheets, and so the effect of increasing membrane distances from 30 to $80 \mathrm{~cm}$ on the
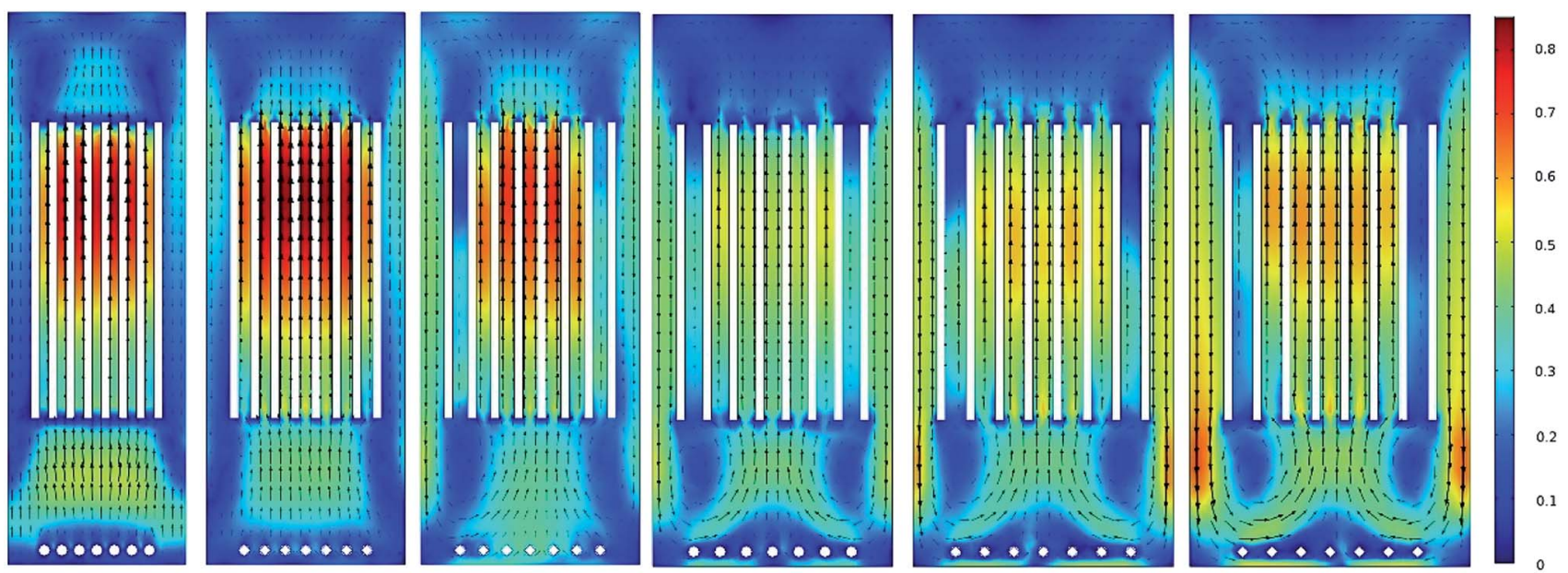

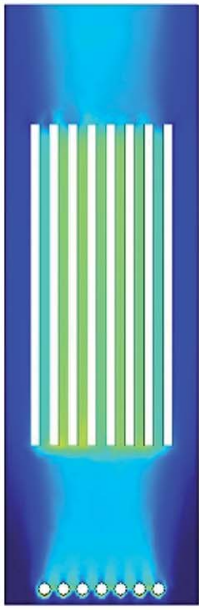

(a)

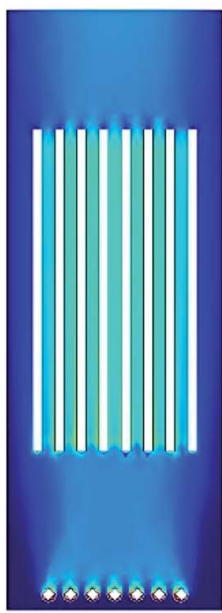

(b)

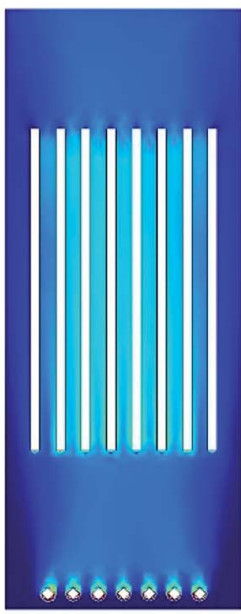

(c)

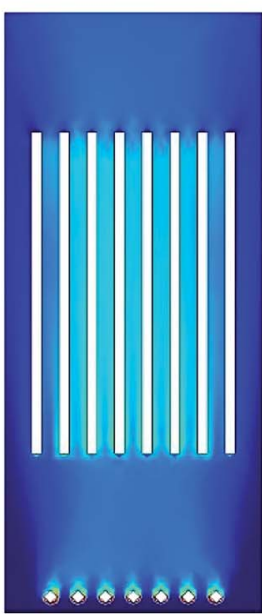

(d)

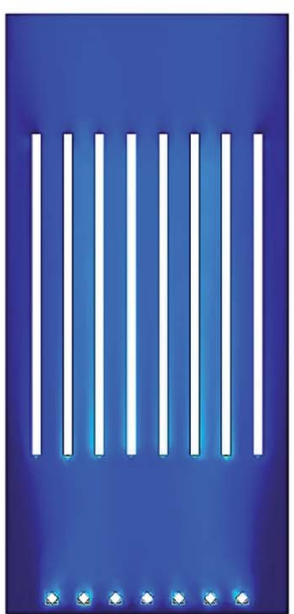

(e)

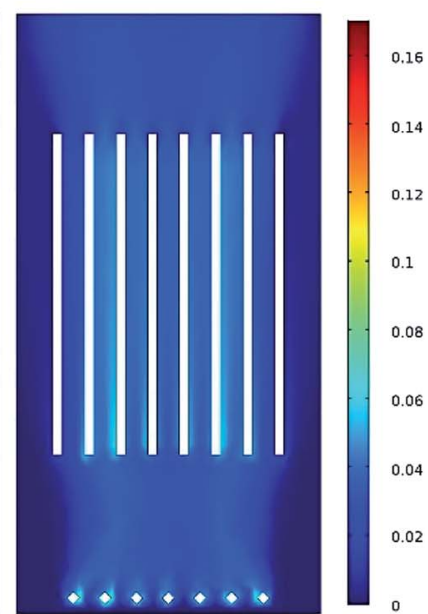

(I)

Fig. 13 Distribution of mean liquid phase velocities and gas volume fractions for different membrane separation distances: (a) $30 \mathrm{~cm}$, (b) $40 \mathrm{~cm}$, (c) $50 \mathrm{~cm}$, (d) $60 \mathrm{~cm}$, (e) $70 \mathrm{~cm}$, (f) $80 \mathrm{~cm}$. 
flow velocity distribution investigated. The distribution of mean liquid phase velocities and gas volume fractions for different membrane spacings at the $y=400 \mathrm{~mm}$ plane are shown in Fig. 13. In all configurations, the liquid phase passes through the middle of the membrane, before reaching the liquid level and flowing downwards. The average flow rates after stabilization were found to be $0.262,0.276,0.287$, $0.257,0.288$ and $0.311 \mathrm{~m} \mathrm{~s}^{-1}$, respectively. The flow rates range is simular to the model in the study of Wu et al. ${ }^{10}$ As the distance from the membrane module to the aeration tube increased, then the overall flow rate of the liquid phase decreases, with gas distribution levels found to be uniform for all five models, resulting in gas content levels of $3.42 \%$, $2.94 \%, 2.66 \%, 2.47 \%, 2.18 \%$, and $1.91 \%$, respectively. Increasing the spacing between the membranes resulted in gas holdup between the membranes gradually decreasing. When the membrane spacing was $30 \mathrm{~cm}$, then the gas accumulates under the membrane because it cannot pass smoothly through the membrane channels. This results in the membrane channel being easily blocked, thus preventing further fluid flow through the channel.

Fig. 14 shows the average shear stress, maximum shear stress and minimum shear stress of the membrane surface for different membrane spacings, with the average shear stress after stabilization found to be $0.038,0.181,0.133$, $0.026,0.085$, and $0.087 \mathrm{~Pa}$, respectively. The average shear stress on the membrane surface reached a maximum when the membrane spacing was set at $40 \mathrm{~mm}$.

\subsection{Hydrodynamic characteristics of an optimized MBR}

Increasing gas flow rates is the simplest way to increase aeration intensity levels, however increasing gas flow rates also result in increased energy consumption. A previous study on MBR structures revealed that a distance of $250 \mathrm{~mm}$ between the membrane and aeration tube was optimal, with our study showing that an aeration tube number of 7 and membrane

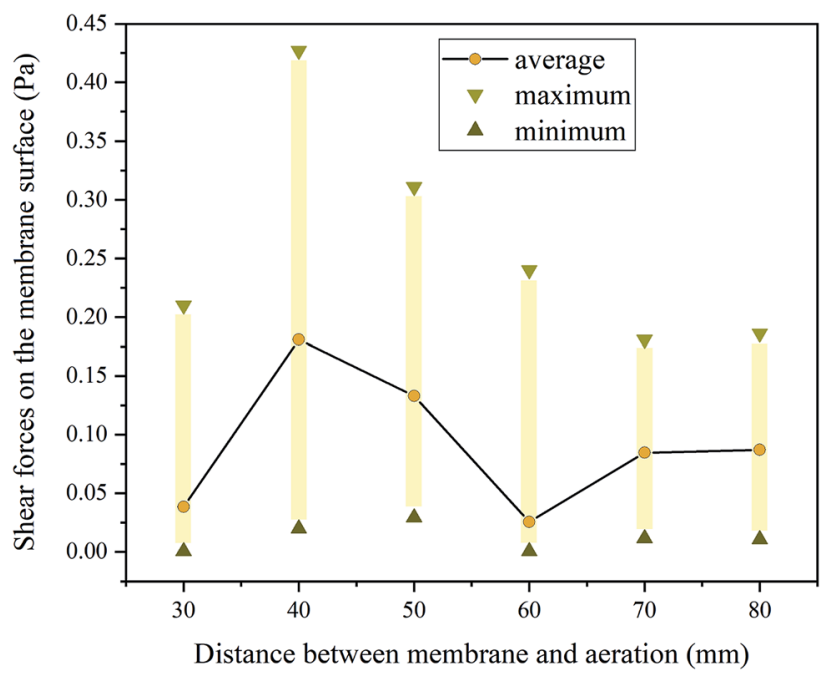

Fig. 14 Shear stresses of membrane surfaces for different separation distances.

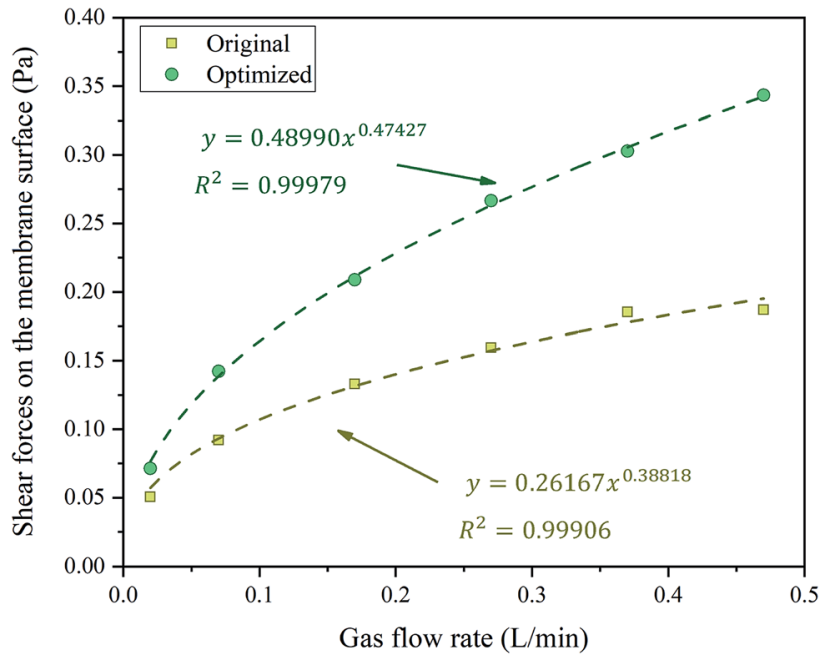

Fig. 15 Comparison of the shear forces experienced by membrane systems for different gas flow rates.

spacing of $40 \mathrm{~mm}$ was optimal for inducing the highest shear stress. The effect of gas flow rates from 0.2, 0.7, 1.7, 2.7, 3.7 to $4.7 \mathrm{~m}^{3} \mathrm{~min}^{-1}$ on fluid flow in MBR were then investigated, with Fig. 15 showing shear stresses at membrane surfaces before and after optimization of gas flow rates. The shear stress of the membrane surface increased for increasing gas flow rates, with the shear stress at an optimized membrane surface being increased from 0.004 to $0.138 \mathrm{~Pa}$ for an aeration volume of 0.57 $\mathrm{m}^{3} \mathrm{~min}^{-1}$. Average flow velocities decreased rapidly for larger rates of aeration, indicating that the gas content in the membrane plate channel rises sharply, resulting in access of the liquid phase to the membrane surface being hindered.

When the gas flow rate was $1.7 \mathrm{~m}^{3} \mathrm{~min}^{-1}$, the membrane surface shear stress levels of the optimized membrane structure was increased from 0.133 to $0.209 \mathrm{~Pa}$, which corresponds to an overall increase of $57 \%$. When the aeration volume was increased to $4.7 \mathrm{~m}^{3} \mathrm{~min}^{-1}$, then the shear stress of the optimized structure was increased from 0.187 to $0.343 \mathrm{~Pa}$, which corresponds to an $83 \%$ increase. In the case of Liu et al. ${ }^{15}$ the shear stress increase $82 \%$ with the aeration intensity increase $150 \%$. When the aeration intensity was from 0.02 to $4.7 \mathrm{~m}^{3} \mathrm{~min}^{-1}$, the optimized cell which can save $57-69 \%$ of energy consumption than of original cell. These results show that the shear force on the surface of membrane can be significantly improved by optimizing the membrane structure and aeration flow rates.

\section{Conclusions}

It is difficult to study structurally complicated MBR structures using real-time measurements and so this study has combined CFD numerical calculations and MBR cold model experimental models to carry out optimization studies on MBRs. These studies have revealed the following results:

(1) A two-phase gas-liquid flow model can be used to effectively simulate MBR performance, with cold model experiments that employ PIV techniques used to generate experimental data 
to validate the results produced by the computational model. Our two-phase simulation studies showed good agreement with experimental results, thus establishing the reliability of the numerical model for MBR optimization studies.

(2) The validated CFD simulation model was used to simulate the effects of varying membrane module height, number of aeration tubes and membrane spacing on liquid phase flow rates, gas holdups and shear stresses of the performance of the membrane surfaces within MBRs.

(3) An optimal design was identified based on an MBR containing $40 \mathrm{~mm}$ spacings between membranes and the use of 7 aerating tubes to introduce gas into the system. This design resulted in the largest shearing force being generated at the bottom of the membrane module at a distance of $250 \mathrm{~mm}$ from the aeration tube. Use of an aeration intensity of $0.02-0.47$ $\mathrm{m}^{3} \min ^{-1}$ in an optimal MBR resulted in shear stress levels that were $50-85 \%$ greater than those generated in a standard MBR system, meaning that the optimal MBR is much less likely to become blocked under these operating conditions.

\section{Conflicts of interest}

There are no conflicts to declare.

\section{Acknowledgements}

We acknowledge the financial support provided by the National Natural Science Foundation of China (Grant 21206038).

\section{References}

1 T. Melin, B. Jefferson, D. Bixio, C. Thoeye, W. De Wilde, J. De Koning, J. van der Graaf and T. Wintgens, Desalination, 2006, 187, 271-282.

2 M. Aslam, A. Charfi, G. Lesage, M. Heran and J. Kim, Chem. Eng. J., 2017, 307, 897-913.

3 A. Drews, J. Membr. Sci., 2010, 363, 1-28.

4 F. Meng, S.-R. Chae, A. Drews, M. Kraume, H. S. Shin and F. Yang, Water Res., 2009, 43, 1489-1512.

5 K. Kimura, N. Yamato, H. Yamamura and Y. Watanabe, Environ. Sci. Technol., 2005, 39, 6293-6299.

6 P. Le-Clech, V. Chen and T. A. G. Fane, J. Membr. Sci., 2006, 284, 17-53.

7 R. Liu, X. Huang, C. Wang, L. Chen and Y. Qian, Process Biochem., 2000, 36, 249-254.

8 Z. Trad, C. Vial, J. P. Fontaine and C. Larroche, Chem. Eng. J., 2015, 282, 77-90.

9 C.-L. Liu, Q.-W. Zhao, Z. Sun, G.-M. Lu and J.-G. Yu, Arabian J. Sci. Eng., 2018, 43, 5965-5976.

10 Q. Wu, X. Yan, K. Xiao, J. Guan, T. Li, P. Liang and X. Huang, Bioresour. Technol., 2018, 249, 402-409.
11 Z. Qing, X. Rongle, Z. Xiang and F. Yaobo, Water Sci. Technol., 2014, 69, 1846-1852.

12 W. Naessens, T. Maere and I. Nopens, Bioresour. Technol., 2012, 122, 95-106.

13 W. Naessens, T. Maere, N. Ratkovich, S. Vedantam and I. Nopens, Bioresour. Technol., 2012, 122, 107-118.

14 M. Yang, D. Yu, M. Liu, L. Zheng, X. Zheng, Y. Wei, F. Wang and Y. Fan, Bioresour. Technol., 2017, 227, 102-111.

15 M. Liu, M. Yang, M. Chen, D. Yu, J. Zheng, J. Chang, X. Wang, C. Ji and Y. Wei, Bioresour. Technol., 2018, 269, 300-308.

16 M. Yang, Y. Wei, X. Zheng, F. Wang, X. Yuan, J. Liu, N. Luo, R. Xu, D. Yu and Y. Fan, Bioresour. Technol., 2016, 219, 566575.

17 N. V. Ndinisa, A. G. Fane, D. E. Wiley and D. F. Fletcher, Sep. Sci. Technol., 2006, 41, 1411-1445.

18 M. Brannock, Y. Wang and G. Leslie, Water Res., 2010, 44, 3181-3191.

19 M. Brannock, G. Leslie, Y. Wang and S. Buetehorn, Desalination, 2010, 250, 815-818.

20 Y. Wang, M. Brannock, S. Cox and G. Leslie, J. Membr. Sci., 2010, 363, 57-66.

21 F. Zamani, A. W. K. Law and A. G. Fane, J. Membr. Sci., 2013, 429, 304-312.

22 Z. Wang, K. Su, T. Shu and W. Wang, Water Sci. Technol., 2017, 76, 2503-2514.

23 E. Radaei, X. Liu, K. H. Tng, G. Merendino, F. J. Trujillo, P. R. Bérubé and G. Leslie, Water Res., 2019, 160, 60-69.

24 K. V. Sharp and R. J. Adrian, AIChE J., 2001, 47, 766-778.

25 C.-L. Liu, Z. Sun, G.-M. Lu and J.-G. Yu, R. Soc. Open Sci., 2018, 5, 171255.

26 R. C. Chen, J. Reese and L.-S. Fan, AIChE J., 1994, 40, 1093-1104.

27 B. Wang, K. Zhang and R. W. Field, AIChE J., 2018, 64, 27212736.

28 C. Liu, Z. Sun, G. Lu, X. Song and J. Yu, Flow Meas. Instrum., 2015, 45, 415-420.

29 X. Liu, Y. Wang, T. D. Waite and G. Leslie, J. Membr. Sci., 2016, 520, 201-213.

30 L. Li, G. A. Al-Muntasheri and F. Liang, Petroleum, 2016, 2, 313-323.

31 C.-L. Liu, Z. Sun, G.-M. Lu, X.-F. Song and J.-G. Yu, Can. J. Chem. Eng., 2015, 93, 565-579.

32 A. Sokolichin, G. Eigenberger and A. Lapin, AIChE J., 2004, 50, 24-45.

33 D. A. Drew, Annu. Rev. Fluid. Mech., 1983, 15, 261-291.

34 M. E. Díaz, A. Iranzo, D. Cuadra, R. Barbero, F. J. Montes and M. A. Galán, Chem. Eng. J., 2008, 139, 363-379.

35 N. Liu, Q. Zhang, G. L. Chin, E. H. Ong, J. Lou, C. W. Kang, W. Liu and E. Jordan, J. Membr. Sci., 2010, 353, 122-134.

36 R. Sengur, G. Deveci, R. Kaya, T. Turken, S. Guclu, D. Y. Imer and I. Koyuncu, Desalin. Water Treat., 2015, 55, 1747-1761. 